\title{
Assessment metrics for littoral seagrass under the European Water Framework Directive; outcomes of UK intercalibration with the Netherlands
}

\author{
Jo Foden
}

Received: 21 July 2006/Revised: 13 September 2006/ Accepted: 15 September 2006/

Published online: 2 January 2007

(C) Springer Science+Business Media B.V. 2007

\begin{abstract}
Under the Water Framework Directive (WFD) taxonomic composition, presence of disturbance sensitive species, abundance and cover are stated attributes for monitoring the status of marine angiosperms; a biological quality element required for assessment of environmental condition. Member States (MS) are required to devise metrics for assessing these attributes to establish ecological status of water bodies. Furthermore the Directive requires intercalibration of metrics and data between MSs. Seagrass are the only truly marine angiosperms. The proposed suites of UK and Dutch metrics for assessing the specified seagrass attributes are described and comparisons made. UK and Dutch metrics are intercalibrated through testing against each nationality's seagrass data. Strong agreement is established in the outcomes of the two suites of tools; $>83 \%$. Differences in outcomes are usually due to lack of availability of raw data. Importantly, where outcomes differ they still fall on the same side of the Good/Moderate boundary.
\end{abstract}

Handling editor: K. Martens

J. Foden $(\square)$

ECOPS, Lowestoft Laboratory, The Centre for Environment, Fisheries \& Aquaculture Science (Cefas), Pakefield Road, Lowestoft, Suffolk NR33 OHT, UK

e-mail: jo.foden@cefas.co.uk
Keywords Ecological status - Intercalibration · Metrics · Seagrass · Water Framework Directive . Zostera spp.

\section{Introduction}

Annex $\mathrm{V}$ of the Water Framework Directive ((WFD) Directive, 2000/60/EC) states that angiosperms are a biological quality element to be used in defining the ecological status of a transitional or coastal water body. Seagrasses are the only truly marine angiosperms and can be used as monitoring objects because they are sensitive to human disturbance (Short \& WyllieEcheverria, 1996). All UK seagrass species are included in the UK Biodiversity Action Plan, 1994, and are considered nationally scarce. Reference conditions for angiosperms in transitional (TW) and coastal waters (CW) are defined:

In TWs the angiosperm taxonomic composition corresponds totally or nearly totally with undisturbed conditions. There are no detectable changes in angiosperm abundance due to anthropogenic activities.

In CWs all disturbance-sensitive angiosperm taxa associated with undisturbed conditions are present. The levels of cover and angiosperm abundance are consistent with undisturbed conditions. (WFD, 2000/60/EC, Annex V) 
These descriptors set out the attributes to be used in monitoring seagrass and the standards to be reached in a water body for it to be considered pristine, i.e. at reference condition. Three metrics have been developed for UK seagrass beds that apply to both TWs and CWs, to meet the monitoring requirements:

- Taxonomic composition (presence of disturbance sensitive taxa)

- Abundance, measured by seagrass bed spatial extent

- Abundance, determined by seagrass shoot density

Scientific justification for these metrics, the establishment of reference conditions and the setting of boundary values for ecological status classes have been explained elsewhere (Foden \& Brazier, 2006).

Two metrics have been developed in the Netherlands, the second of which contains submetrics currently under consideration:

- Seagrass area

- Seagrass quality: sub-metric 1, species; sub-metric $2 \& 3$, mean coverage within the field and distribution in covering class; and sub-metric 4, trend of the area development

This paper presents an overview of these two suites of metrics and compares them by testing against international datasets. The WFD process requires sites for which data are available within the North East Atlantic Geographic Intercalibration Group (NEA GIG) areas NEA4, NEA11 and NEA2 6 to be compared for the purposes of intercalibration ((WFD) Directive 2000/60/EC). The UK and Netherlands (NL) are able to intercalibrate by pairing similar metrics from each country and comparing the outcomes when tested on data from selected water bodies in both countries. Member States (MS) such as Republic of Ireland (RoI) are making suitable data available with the intention of adopting metrics in line with those of the UK. Other protocols are being developed for vegetation metrics in other NEAGIG areas and this paper does not deal with the overall classification of the ecological status of water bodies.
The WFD requires MSs to type water bodies according to specific factors: for TWs these are mixing characteristics, salinity, tidal range, exposure, depth and substrate; and for CWs salinity, tidal range and exposure ((WFD) Directive 2000/ $60 / \mathrm{EC})$. Intercalibration is then conducted in waterbodies of the same type. However, intercalibration of seagrass metrics has been carried out between participating MSs with different NEA types, because seagrass habitats correspond across these types. The metrics are applicable where littoral habitats correspond, regardless of typology in which they occur. Littoral seagrass beds are considered a habitat and as such may occur in more than one NEA type, where habitat and environmental conditions are suitable.

\section{Methods}

In order to intercalibrate the UK and NL metrics a study was carried out to establish how reference conditions for each nation had been derived, how the suites of metrics were developed and what the boundary conditions were between each ecological class. Similar metrics could then be identified, paired and compared, to find commonalities. Table 1 provides an over-view of the UK and NL metrics, and presents the boundary values for each ecological status class (from Foden \& Brazier, 2006). The metrics are further described in the following sections.

\section{Reference conditions}

No reference sites for seagrass were identified in the water bodies of participating MSs. Seagrass beds are naturally highly variable in extent, abundance, species composition and biomass, dependant on a variety of factors; e.g. geographical location, substrate, hydrodynamic regimes. It was not possible to identify with certainty reference sites on which to base reference conditions for every combination of these factors, for each water type.

Each MS set its reference conditions for the typologies in which seagrass are found. Although the typologies suitable for seagrass beds differ between countries the habitats in which they are 


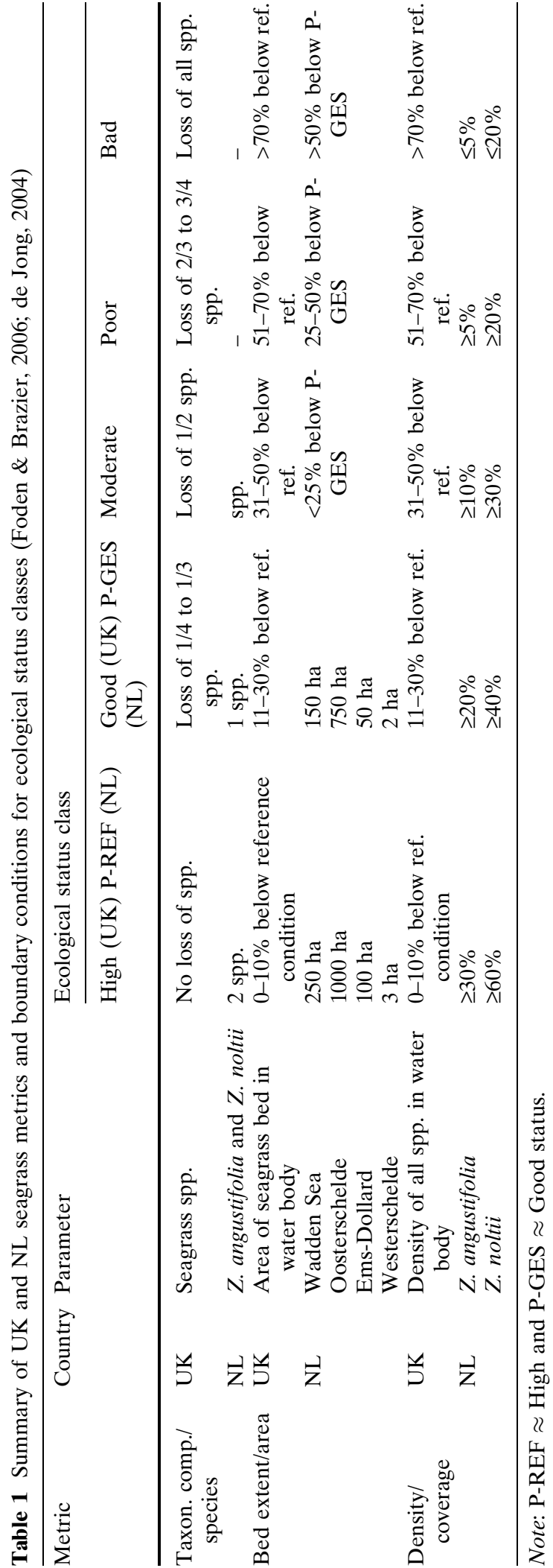

found are similar. The UK approach establishes reference condition values using historic data, where such data exist. Expert judgement then refines the reference conditions to be the maximum potential seagrass species, area and abundance, in natural hydrodynamic and physicochemical state, for individual water bodies (Foden \& Brazier, 2006).

In the Netherlands seagrass beds have been regularly monitored by the RWS Dutch National Institute for Coastal and Marine Management (RWS-RIKZ, in cooperation with RWS-AGI) since the 1980s. Seagrass occur in only four Dutch water bodies and reference conditions were developed individually for each of these (see Table 1). A combined approach was used to set reference condition values for each of the attributes using historic data, knowledge of the current area and modelling of potential habitat. The potential habitat modelling approach was used as most water bodies have undergone large changes in hydromorphological conditions making historic data of limited relevance to current conditions. The modelling is further described, below (Bed Extent $(U K) /$ Area $(N L))$. Expert judgement is relied upon to synthesise these data in the setting of reference conditions for water bodies (de Jong, 2004).

Reference conditions and Good ecological status have to be valid for a natural situation, which is unrealistic because Dutch water bodies are embanked and classed as heavily modified. Although the water bodies are managed and protected by engineering, habitats such as seagrass beds have established naturally within them. Potential Reference Conditions (P-REF) and Potential Good Ecological Status (P-GES) are the highest two classes heavily modified water bodies can attain, and scientists in the Netherlands have used the approach described above to set values for these by focussing on the current situation in the water bodies concerned (de Jong, 2004). P-REF and P-GES for seagrass in Dutch heavily modified water bodies are equivalent to High (or Reference) status and Good status in UK water bodies that are not heavily modified because the presence of seagrass habitats is natural in both. 
Taxonomic composition (UK)/species (NL)

The UK metric of 'Taxonomic composition' is based on four as being the maximum possible number of seagrass species in a water body (Foden \& Brazier, 2006). The species of seagrass found in the UK are Zostera noltii Hornem., Z. marina L. and Z. angustifolia Hornem. (Davison \& Hughes, 1998). Outside the UK Z. angustifolia is frequently regarded to be a littoral, annual ecotypic or phenotypic form of perennial Z. marina (den Hartog, 1972); called Z. marina var. angustifolia. However, in most UK literature the two species are made distinct. Ruppia spp. (commonly known as widgeon grass) are poikilosaline aquatic plants and although they are not strictly considered as part of the traditional seagrass arrangement (Kuo \& den Hartog, 2001), they often co-occur with Zostera and have generally been considered as seagrass by fieldworkers. Reference conditions are based on the maximum number of species historically recorded in a water body, which will be between 1 and 4 . The level of deviation from reference conditions determines ecological status for taxonomic composition (Table 1).

The NL metric of 'Species' is based on a maximum of two for a water body. In all Dutch water types and water systems species of dwarf grass-wrack (Z. noltii) and littoral eelgrass (Z. angustifolia) may occur, sometimes together, but usually more or less separated related to somewhat deviating growing conditions (de Jong, 2004). As recently as 1920 sublittoral eelgrass (Z. marina) was recorded in the transition zone between the Zuiderzee and the Wadden Sea, but disappeared following the damming of the Zuiderzee and no longer occurs anywhere in the Netherlands (de Jong, 2004). Table 1 presents the values for the Dutch 'species' metric for the ecological status classes of P-REF and P-GES. Loss of both species is classed as poor ecological status.

\section{Bed extent (UK)/Area (NL)}

Reference conditions for bed extent in UK water bodies are based on historic data (whenever such data exist) and expert judgement. Seagrass data are not comparable across geographic regions, as naturally occurring, local physical conditions may cause significant natural change. Rather, reference conditions have been established for individual water bodies using historic data representing its healthiest previously recorded condition, and modified by expert judgement if this is unrealistic. A bed's current extent is then compared against these reference conditions and the level of deviation establishes the status class for bed extent (Table 1).

In Dutch water bodies the amount of seagrass present in the reference situation without embankments was unknown but an assumed area of $5-10 \%$ of the total area of the waterbodies in the types CW-NEA4 (sheltered coastal waters) and TW-NEA11 (transitional waters) would support one or more species of seagrass (de Jong, 2004). The NL approach then uses a combination of historical data (maximum known area), current data (current area) and potential area (modelled potential habitat maps). Potential area was determined where seagrasses potentially could occur, based on the most important environmental factors; period of emergence, hydrodynamics (flow velocity and waves) and salinity. This produced a potential map for each water body and showed the difference between this map and the actual distribution in a period in which the situation was relatively optimal. As circumstances vary strongly between water bodies, e.g. in transparency, eutrophication, hydrodynamics (Wijgergangs \& de Jong, 1999), a general PREF and P-GES per typology was of little relevance and therefore only a P-REF/P-GES per water body was been formulated. Expert judgement is relied upon to synthesise these data in the setting of reference conditions for water bodies (de Jong, 2004) (Table 1).

\section{Density (UK)/coverage (NL)}

Natural variability in density of seagrass is high in shallow water where populations are disturbed by physical parameters and average values across geographic regions do not adequately describe growth regulation by resources (e.g. KrauseJensen et al., 2003). The proposal for UK water bodies, therefore, is that seagrass density data are 
not compared across geographic regions, as naturally occurring, local events and physical parameters may cause significant natural change. Rather, an individual bed's current density is compared against historic data representing its healthiest previously recorded condition. There is no division made between the different seagrass species that may comprise the bed. As with other metrics, ecological status reflects the degree of deviation from reference condition (Table 1).

The coverage (i.e. the density) of seagrass in a field is not the same for both species in Dutch water bodies; principally dwarf grass-wrack (Z. noltii) may occur in much larger coverages (up to $100 \%$ ) than littoral eelgrass (Z. angustifolia) (to a maximum of some $50-60 \%$ ). The metric derived from this is that the seagrass fields present in the water body are to contain the higher coverages above a certain minimum level, taking the species into account. The metric for seagrass coverage is based on the mean coverage per species and is shown in Table 1, along with the boundary values for lower ecological status classes. For a water body with both species the cover of $Z$. noltii is considered, as this is generally the more common species; $Z$. angustifolia usually appears as patches within a $Z$. noltii bed. If only one species occurs this is accounted for (de Jong, 2004).

Trends in seagrass abundance

Duarte \& Kirkman (2001) found the time frame to determine real changes brought about by most human disturbance may take 5-10 years, unless disturbance is catastrophic such as habitat removal for coastal redevelopment. Strong fluctuations in area and density of seagrass are possible due to climatic (and apparently coincidental) circumstances, in particular in littoral eelgrass (Z. angustifolia) (de Jong, 2004). Consequently the UK proposes classification status for density is determined by the underlying trend over a period of 5-6 years, where data exist (Foden \& Brazier, 2006). This will significantly reduce noise created by natural variability and can be designed to coincide with the WFD's reporting cycle (WFD, 2000/60/EC, Annex V). The trend for an individual bed and the loss or gain, as compared with reference conditions, can be used as a supporting parameter to the other metrics to identify whether the seagrass bed is in a state of degradation or recovery.

Often trends in area and density can be identified in the Dutch data (de Jong, 2004) (e.g. Fig. 2a-c). A negative trend is an indication of deterioration in water quality making the seagrass less abundant and thus can act as an early warning system. The proposal by the Netherlands is that a positive trend suggests an ecological status of greater than Moderate and a negative trend suggests Moderate status or below.

\section{Results}

Comparison of UK and NL metrics

When comparing the UK metric of 'taxonomic composition' with the Dutch metric of 'species' the most obvious difference is the potential for UK metrics to define all five ecological status classes for a water body, whereas only P-REF and P-GES can be defined for NL water bodies (Table 1). In practicality there are very few UK water bodies with more than two seagrass species; most commonly mono-specific or 2-species seagrass beds are extant (Foden \& Brazier, 2006). The results of testing this pair of metrics against UK and Dutch data show remarkable commonality in the final outcomes (next section).

There are significant similarities in the NL and UK ecological status classes' boundary conditions for seagrass bed extent (UK)/area (NL) metrics. With only four water bodies the NL has been able to use modelling and expert judgement to set precise bed areas for P-REF and P-GES for each of them. The correlation between the two nations' metrics appears in the percentage differences between boundary classes. For example, the PREF and P-GES values for NL water bodies vary between $25 \%$ and $50 \%$, with a mean difference of $37 \%$. This is very close to the UK's boundary of a $30 \%$ decrease in bed extent between High and Good status. Between P-REF and Moderate values for the NL's four water bodies there is a difference of $53 \%$. Between P-REF and Poor the percentage change is $69 \%$ and between $\mathrm{P}-\mathrm{REF}$ 
and $\mathrm{Bad},>69 \%$. All of these boundaries broadly align with the UK metric's boundary conditions for each status class.

Though not exactly the same, there are also significant similarities between the NL and UK ecological status classes' boundary conditions for seagrass coverage (NL)/density (NL). For example, the Netherlands has identified precise density ranges for $Z$. noltii and $Z$. angustifolia, for P-REF and P-GES. The boundary between these two classes is a $1 / 3$ loss in density for either species, which is broadly in line with the UK boundary of a $30 \%$ difference between High and Good. The boundary conditions between the other status classes for density changes are broadly aligned for the two countries (Table 1) and have been tested on seagrass data (see Results).

With regards to the supporting parameter of trends in abundance, both NL and UK agree that this should show a stable seagrass bed (at the maximum potential identified for a water body). If abundance is less than would be expected for High or P-REF then abundance should show a positive underlying trend, indicative of recovery. Conversely, a negative trend in seagrass abundance is undesirable, indicative of degradation, and would signal a potential deterioration in ecological class. Furthermore, the MSs agree that the ideal period over which to consider the trend in abundance is $\sim 6$ years, designed to coincide with the WFD reporting cycles.

\section{Testing NL and UK metrics against Dutch} water body data

Table 2 presents the data and outcomes of testing for each of the four Dutch water bodies under consideration; Wadden Sea, Oosterschelde, EmsDollard and Westerschelde (locations shown in Fig. 1a). As reference conditions (P-REF) have been individually set for each water body, these have been reproduced in this table, along with records of the current situation (from de Jong, 2004). The degree of deviation of current records from P-REF has been cross-referenced with Table 1 and the metric outcomes for NL and UK are summarised.

For the Wadden Sea, the three outcomes for NL and UK metrics are in agreement (Table 2a).
Both historically recorded species (Z. noltii and $Z$. angustifolia) are currently present and indicate P-REF or High status. The current area represents only $19 \%$ of P-REF, which is Bad status under the UK metric scheme (Table 1). Previous highest recorded density was $58 \%$ in 1997 and under the UK metric the current situation of $40 \%$ is Good.

The underlying trends in both seagrass bed extent (area) and density could be described as positive or neutral (Fig. 2a). So although the size of the bed is very small compared with the P-REF of 250 ha, seagrass in the Wadden Sea are possibly in a recovery phase.

There is also accord between the national suites of metrics for the Oosterschelde data (Table 2b). Both species of historically recorded seagrass are still present. The current area of 94 ha is $<10 \%$ of P-REF, indicating Bad status. Z. noltii is the species considered for the density metric as it dominates the species composition; Z. angustifolia (littoral eelgrass) constitutes a very small proportion of the overall seagrass area at very low density therein (de Jong, 2004). The current $Z$. noltii density is greater than the lower limit set as the Oosterschelde's P-REF.

The underlying trend in seagrass bed extent (area) is strongly negative between 1973 and the beginning of the 1990s (Fig. 2b). Since then it has become neutral, with possibly a very slight increase in recent years. The trend in density could be described as neutral as there has been consistently low percentage cover.

The outcomes for the NL and UK metrics for the Ems-Dollard are the same in two instances, but differ for taxonomic composition/species (Table 2c). Z. noltii has never been recorded in this water body and the overall seagrass area is comprised of $Z$. angustifolia (littoral eelgrass) at low densities. In the absence of any historical record for $Z$. noltii the UK classification would be High for this metric. However, the Dutch classification is one class lower, at P-GES. The diminished size of bed compared with reference condition classifies the water body as Bad under both countries' area metrics. Similarly the sparse cover of Z. angustifolia results in a Moderate outcome under UK and NL metrics. 
Table 2 P-REF and PGES for four Dutch water bodies (de Jong, 2004) and the outcomes of testing UK and NL metrics on data for; (a) Wadden Sea, (b) Oosterschelde, (c) EmsDollard and (d)

Westerschelde

$\mathrm{P}-\mathrm{REF} \approx \mathrm{High}$ and $\mathrm{P}-\mathrm{GES} \approx$ Good status

\begin{tabular}{|c|c|c|c|}
\hline & \multicolumn{3}{|l|}{ Metrics } \\
\hline & Taxa/Species & Area/bed extent & Coverage/bed density \\
\hline \multicolumn{4}{|l|}{ (a) Wadden Sea } \\
\hline NL P-REF & 2 species & 250 ha & $\begin{array}{l}\text { Z. } \text { angustifolia }=\geq 30 \\
\text { Z. } \text { noltii }=\geq 60\end{array}$ \\
\hline NL P-GES & 1 species & 150 ha & $\begin{array}{l}Z \text {. } \text { angustifolia }=\geq 20 \\
\text { Z. } \text { noltii }=\geq 40\end{array}$ \\
\hline Current situation & 2 species & 47 ha & Z. noltii $\approx 40 \%$ \\
\hline NL outcome & P-REF & Bad & P-GES \\
\hline UK outcome & High & Bad & Good \\
\hline \multicolumn{4}{|l|}{ (b) Oosterschelde } \\
\hline NL P-REF & 2 species & 1000 ha & $\begin{array}{l}Z \text {. } \text { angustifolia }=\geq 30 \\
Z \text {. } \text { noltii }=\geq 60\end{array}$ \\
\hline NL P-GES & 1 species & 750 ha & $\begin{array}{l}Z \text {. } \text { angustifolia }=\geq 20 \\
Z \text {. } \text { noltii }=\geq 40\end{array}$ \\
\hline Current situation & 2 species & 94 ha & Z. noltii $\approx 62 \%$ \\
\hline NL outcome & P-REF & Bad & P-REF \\
\hline UK outcome & High & Bad & High \\
\hline \multicolumn{4}{|l|}{ (c) Ems-Dollard } \\
\hline NL P-REF & 2 species & 100 ha & Z. angustifolia $=\geq 30$ \\
\hline NL P-GES & 1 species & 50 ha & Z. angustifolia $=\geq 20$ \\
\hline Current situation & 1 species & 14 ha & Z. angustifolia $\approx 13 \%$ \\
\hline NL outcome & P-GES & Bad & Moderate \\
\hline UK outcome & High & Bad & Moderate \\
\hline \multicolumn{4}{|l|}{ (d) Westerschelde } \\
\hline NL P-REF & 2 Species & 3 ha & $\begin{array}{l}Z \text {. } \text { angustifolia }=\geq 30 \\
Z \text {. } \text { noltii }=\geq 60\end{array}$ \\
\hline NL P-GES & 1 Species & 2 ha & $\begin{array}{l}Z \text {. } \text { angustifolia }=\geq 20 \\
\text { Z. } \text { noltii }=\geq 40\end{array}$ \\
\hline Current situation & 1 Species & 2 ha & Z. noltii $\approx 5-20 \%$ \\
\hline NL outcome & P-GES & P-GES & Poor (possibly Bad) \\
\hline UK outcome & High & Good & Moderate or Poor \\
\hline
\end{tabular}

The trend in seagrass bed extent (area) is positive from 1986 to 2004, but this belies the fact that there was a sharp fall in area in 2004 (Fig. 2c). The trend in density could be described as negative with the 2004 value being one of the lowest since 1988.

Z. noltii in the Westerschelde forms a small bed, situated in the harbour of Flushing-east, with an uncertain history. It might be that $Z$. noltii was present in the past, before the construction of the harbour, in the Sloe inlet between the two islands Walcheren (western side) and South Beveland (eastern side), but no records are available. Equally it might that it appeared there after the construction of the harbour (de Jong, 2004). It is only mapped during surveys of the small salt marsh here. The cover is low, as it is a patchy bed in between the Spartina tussocks on the seaward side of the marsh. Estimated mean cover is between 5 and $20 \%$ (de Jong, 2004).

The outcomes for the NL and UK metrics are the same for area (bed extent) as 2 ha represents $2 / 3$ of reference. However, outcomes differ for species composition and bed density (Table 2d). The absence of raw data means it is difficult to precisely establish an ecological class for these metrics and prevents a temporal trend plot over recent years for the Westerschelde.

Testing NL and UK metrics against UK water body data

Historic datasets are rare in the UK as there has not been a national seagrass monitoring programme. For many of those sites that have been surveyed, monitoring has been on a local scale and 

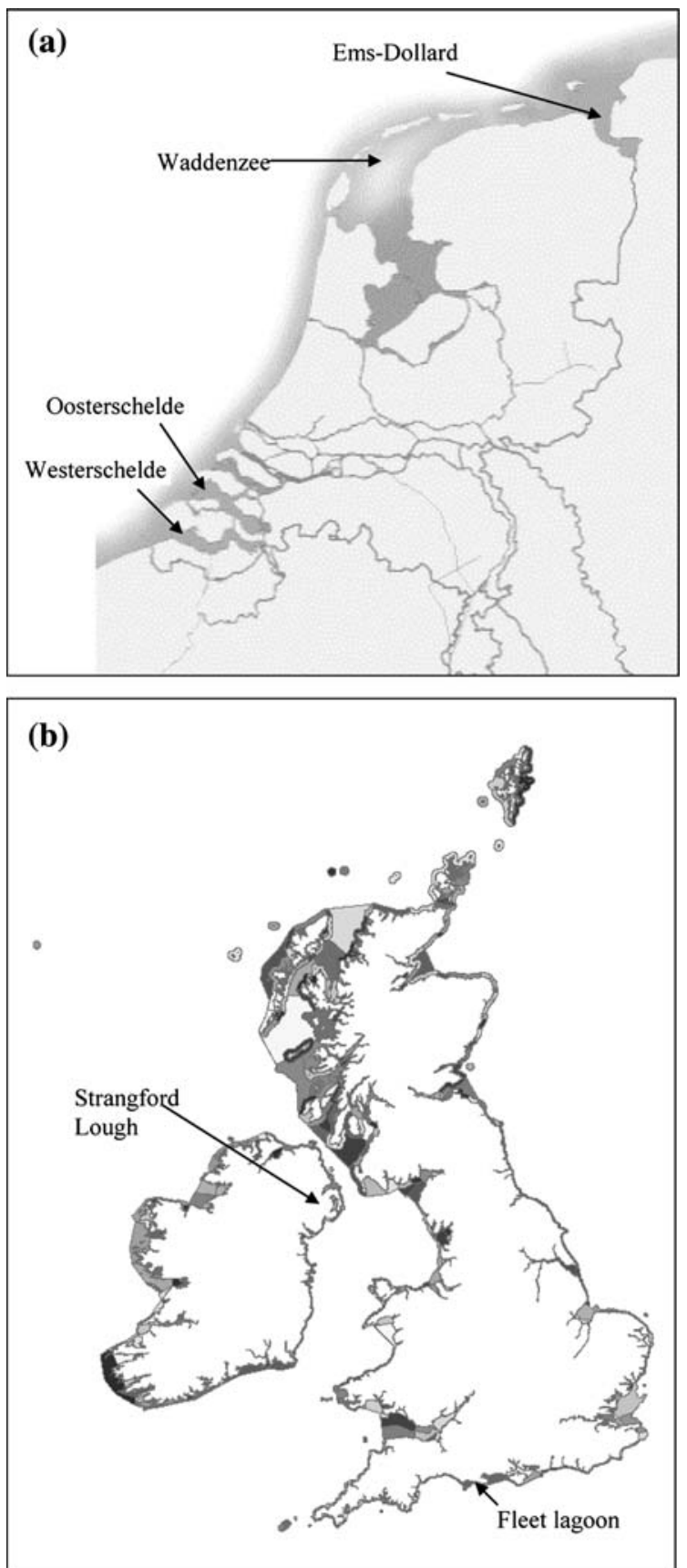

Fig. 1 Map of the seagrass regions used in the intercalibration exercise in; (a) Netherlands and (b) UK

has likely employed one of a variety of methods, resulting in data that may not be fit for the purposes of WFD assessment. The Strangford Lough and Fleet Lagoon water bodies (Fig. 1b) have been chosen for testing because their data are comprehensive enough to be able to apply the metrics.

Although historical data are scarce in Northern Ireland, there has clearly been a marked decline in the distribution of seagrasses since 1930s (Portig, 2004). This has been coupled with a change in the dominant Zostera spp. present in the intertidal areas with $Z$. marina in its perennial form dominant in the 1930s being replaced by Z. noltii and Z. angustifolia by 1970 (Portig et al., 1994). In Strangford Lough there has been a general improvement in the status of Zostera spp. particularly in the northern end during the last 10 years. Table 3 a shows the results of testing UK and NL metrics against the available data for Strangford Lough. The taxonomic composition of seagrass in the water body is at reference condition. Setting a reference condition for area is difficult given the lack of historic data, but as the beds have been expanding in size for the last 10 years it is reasonable to assume they are in a 'recovery' phase and have yet to reach maximum potential area. The mapped beds cover a large proportion of the littoral and the area is likely to be at $>50 \%$ of its maximum potential, but employing the precautionary principle the assumption is they may not yet cover as much as $70 \%$ of their potential. This classifies it as Moderate. The mean seagrass density for all N.I. (Northern Ireland) loughs is 52\% (Portig, 2004) and this has been taken as reference condition for density. Strangford Lough's seagrass density currently exceeds this and is therefore High status for both nationalities' metrics.

The underlying trend in seagrass density (from Portig, 2004) is positive over the 4 survey years, supporting the judgement of the seagrass being in a 'recovery' phase.

A detailed survey of species composition and density was conducted for seagrass in Fleet lagoon during 2002 (Bunker et al., 2004). The reports on area are more qualitative and less exact. The outcomes for the NL and UK metrics are the same in all three instances (Table 3b). Species composition remains unchanged from historic surveys. With regard to area, Z. marina has been lost from the Swannery in the lagoon since 1982, but a north-westward extension of 

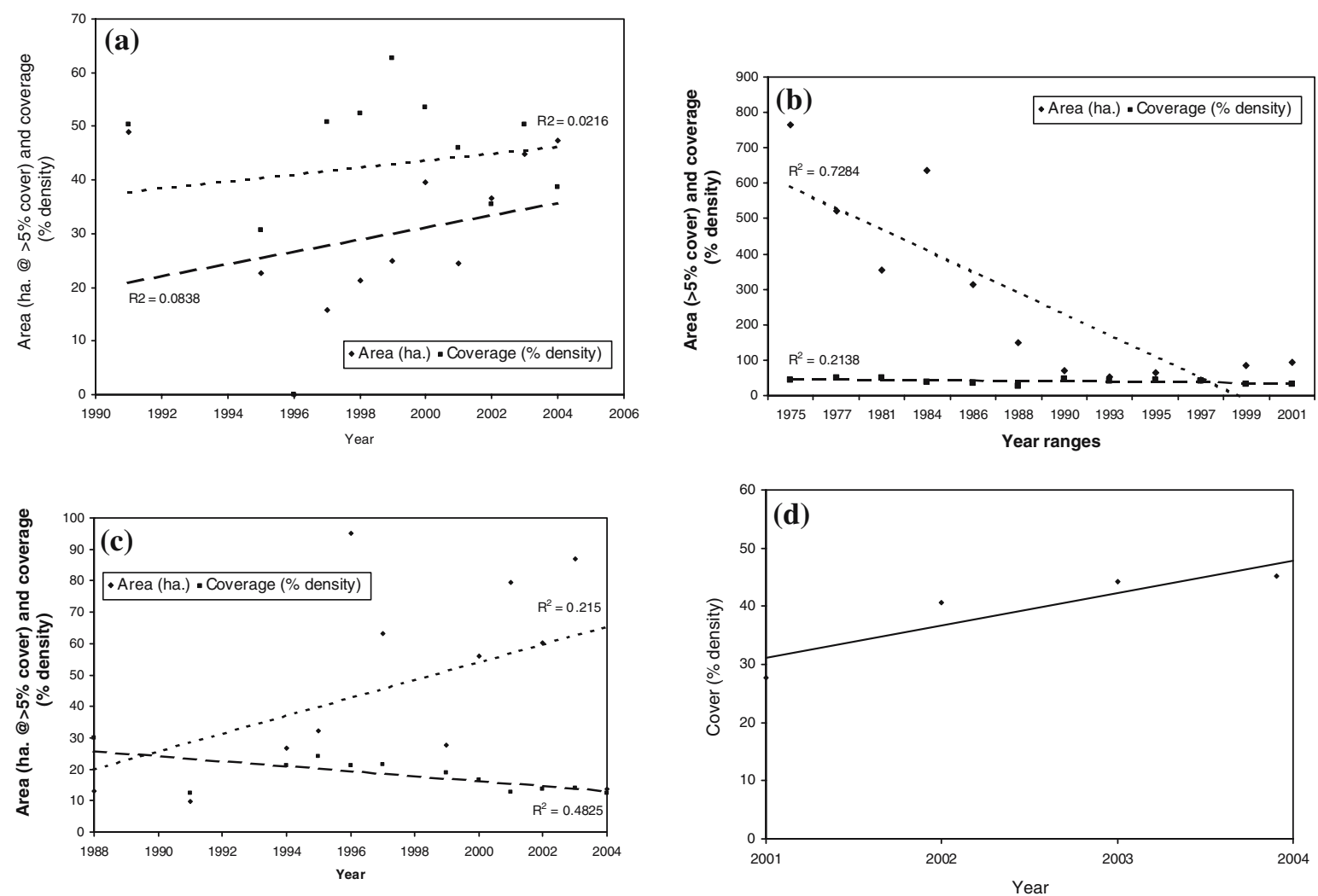

Fig. 2 Temporal trends in area and density of seagrass in three Dutch and one UK water bodies; (a) Wadden Sea, (b) Oosterschelde, (c) Ems-Dollard and (d) density only in Strangford Lough

Z. noltii range has occurred in West Fleet since 1999. Ruppia sp. has been lost from Swannery Basin and west of Berry Coppice since in 1983, but distributions in the rest of the Fleet remain broadly unchanged since 1999 (Bunker et al., 2004). No further loss is evident but there are limited data available, as only broad area of occurrence has been noted and no surveys have fully mapped area. Seagrass are widespread in the lagoon but are unlikely to be at their maximum potential extent; using the precautionary principle the assumption is $50-70 \%$ of maximum. Density remains broadly unchanged from previous surveys (since 1983) and known historic data. The lack of raw data from previous surveys limits statistical comparison (Bunker et al., 2004) and there is the possibility of density being at less than reference condition and a precautionary Good status has been assigned. There are insufficient raw data available to chart trends in seagrass bed area or density.

\section{Discussion}

The comparability of participating Member States' metrics has been tested using data from six different water bodies. In summary 18 metric tests were carried out on the metrics of NL and UK. Overall there is agreement for 15 metric tests, which is compliance of $>83 \%$.

Where NL outcomes differ from UK metrics these differences are explicable. For Ems-Dollard the species composition metric outcomes were High for UK and P-GES for NL, reflecting national differences in the way reference conditions for species composition are set. The outcomes for species composition metric are also different for Westerschelde, but it is the lack of historic data to confirm $Z$. noltii as having been historically present that results in a class of High for the UK metric. The third difference in outcome between NL and UK is for the density metric in Westerschelde. This difference is likely to be of 
Table 3 Current situation of seagrass in (a) Strangford Lough (Portig, 2004) and (b) Fleet lagoon (Bunker et al., 2004), and outcomes of testing UK and NL metrics

\begin{tabular}{|c|c|c|c|}
\hline & \multicolumn{3}{|l|}{ Metrics } \\
\hline & Species composition & Area/bed extent & Coverage/bed density \\
\hline \multicolumn{4}{|l|}{ (a) Strangford Lough } \\
\hline Current situation & $\begin{array}{l}\text { Z. angustifolia, } Z \text {. noltii, } \\
\text { Z. marina, Ruppia spp. }\end{array}$ & 924 ha & $\begin{array}{l}53 \% \text { mean density for } \\
\text { all species. }\end{array}$ \\
\hline NL outcome & P-REF & Moderate & P-REF \\
\hline UK outcome & High & Moderate & High \\
\hline \multicolumn{4}{|l|}{ (b) Fleet Lagoon } \\
\hline Current situation & $\begin{array}{l}\text { Z. marina, Z. noltii } \\
\text { and Ruppia spp. }\end{array}$ & $\begin{array}{l}\text { Some loss recorded. Limited } \\
\text { data; assume } 50-70 \% \text { of maximum } \\
\text { potential }\end{array}$ & $\begin{array}{l}\text { Broadly unchanged. } \\
\text { Statistical comparison limited }\end{array}$ \\
\hline NL outcome & P-REF & Moderate & P-GES \\
\hline UK outcome & High & Moderate & Good \\
\hline
\end{tabular}

Note: $\mathrm{P}-\mathrm{REF} \approx \mathrm{High}$ and $\mathrm{P}-\mathrm{GES} \approx$ Good status

minor significance for two reasons; raw data are not available to allow a more precise setting of class under the UK metric, and both nationalities' outcomes are less than Good, meaning a programme of investigative measures would be undertaken. All metric tests on other water bodies showed parity in their outcomes for UK and NL.

The temporal trends in abundance data are useful supporting metrics and can act as an early warning system where deterioration in ecological quality may be starting to happen. Examination of trend data is not a specific parameter to be assessed under the Directive but it is recommended by both MSs.

Importantly where there are differences between the nationalities' metric outcomes, the classifications still fall on the same side of the Good-Moderate boundary. This boundary is significant because water bodies falling below Good status will be subject to further monitoring to identify the causes ((WFD) Directive 2000/60/EC) and remedial action must be taken to improve ecological quality. This may be a costly process.

MSs individually developed national metrics for angiosperm ecological assessment, and yet there is strong agreement between nationalities' metrics, as presented in this paper. The WFD is the first Directive to base classification on ecological status and this intercalibration process adds confidence to the reliability of assessments made using MSs proposed suites of tools.

\section{References}

Bunker, F., T. Mercer \& C. Howson, 2004. Fleet lagoon and tidal rapids survey 15 th-22nd July 2002. Report to English Nature, 80 pp.

Davison, D. M. \& D. J. Hughes, 1998. Zostera Biotopes (Volume 1). An overview of dynamics and sensitivity characteristics for conservation management of marine SACs. Scottish Association for Marine Science (UK Marine SACs Project), 95 pp.

Den Hartog, C., 1972. The identity of Zostera marina var. angustifolia Hornemann (Potamogetonaceae). Blumea 20: 150 .

de Jong, D. J., 2004. Water Framework Directive: determination of the reference condition and PotentialREF/Potential-GES and formulation of indices for plants in the coastal waters CW-NEA3 (K1), CW-NEA4 (K2), CW-NEA1 (K3), transitional water, TW-NEA11 (O2), and large saline lakes, NEA26 (M32), in the Netherlands. (document RIKZ/OS/ 2004.832.x).

Duarte, C. M. \& H. Kirkman, 2001. Methods for the measurement of seagrass abundance and depth distribution. In Short, F. T. \& R. G. Coles (eds), Global Seagrass Research Methods. Elsevier Science B.V., Amsterdam, 141-153.

Foden, J. \& D. P. Brazier, 2006. Angiosperms (seagrass) within the EU Water Framework Directive; a UK perspective. Marine Pollution Bulletin (in press).

Krause-Jensen, D., M. F. Pedersen \& C. Jensen, 2003. Regulation of eelgrass (Zostera marina) cover along depth gradients in Danish coastal waters. Estuaries 26: 866-877.

Kuo, J. C. \& C. den Hartog, 2001. Seagrass taxonomy and identification key. In Short, F. T. \& R. G. Coles (eds), Global Seagrass Research Methods. Elsevier Science B.V., Amsterdam, 31-55. 
Portig, A. A., 2004. The distribution of intertidal Zoster$a$ spp. in Northern Ireland, 2003. Report for Environment \& Heritage Service, 84 pp.

Portig, A. A., R. G. Mathers, W. I. Montgomery \& R. N. Govier, 1994. The distribution and utilisation of Zostera species in Strangford Lough, Northern Ireland. Aquatic Botany 47: 317-328.

Short, F. T. \& S. Wyllie-Echeverria, 1996. Natural and human-induced disturbances of seagrasses. Environmental Conservation 23: 17-27.
Water Framework Directive 2000/60/EC. European Communities Official Journal L327 22.12.2000, 73 pp.

Wijgergangs, L. J. M. \& D. J. de Jong, 1999. Een ecologisch profile van zeegras en de verspreiding in Nederland. (An ecological profile of sea grasses and their distribution in the Netherlands.) KUN/RIKZ. Katholieke Universiteit Nijmegen Vakgroep Oecologie; Rijkswaterstaat RijksInstituut voor Kust en Zee/ RIKZ, Middelburg, 75. 